\title{
Laju Paparan Radiasi Sinar-X pada Dinding Laboratorium Diagnostik ATRO Bali
}

\author{
X-Ray Radiation Exposure Rate on the Walls of ATRO Bali \\ Diagnostic Laboratory
}

\author{
Nunung Purwati Dewi ${ }^{{ }^{*}}$, Ni Luh Putu Trisnawati ${ }^{1}$, Maghfirotul Iffah ${ }^{2}$ \\ ${ }^{1}$ Program Studi Fisika, Fakultas Matematika dan Ilmu Pengetahuan Alam, Universitas Udayana, \\ Kampus Bukit Jimbaran, Badung, Bali, Indonesia 80361 \\ ${ }^{2}$ Akademi Teknik Radiodiagnostik dan Radioterapi (ATRO) Bali, Jalan Tukad Batanghari VII No. 21, \\ Dauh Puri Klod, Denpasar Barat, Denpasar, Bali, Indonesia, 80234 \\ Email: *nunungpurwatidewi@student.unud.ac.id; trisnawati@unud.ac.id; magfirotul.iffah@gmail.com
}

\begin{abstract}
Abstrak - Telah dilakukan penelitian mengenai laju paparan radiasi sinar-X pada dinding laboratorium diagnostik ATRO Bali. Dosis paparan radiasi sinar-X diukur menggunakan surveymeter di dalam dan di luar ruangan pada dinding penahan radiasi primer $(A)$, dinding penahan radiasi sekunder $(B$ dan $D)$ dan dinding penahan radiasi bocor $(C)$ dengan mengatur faktor eksposi pada tegangan tabung $80 \mathrm{kV}$, arus tabung $200 \mathrm{~mA}$ dan waktu 0,160 detik. Hasil pengukuran dosis paparan radiasi pada suatu dinding digunakan untuk menghitung laju paparan radiasi rata-rata. Hasil perhitungan rata-rata laju paparan radiasi sinar-X pada dinding A sebesar $1,106 \times 10^{-7} \mathrm{mR} / \mathrm{h}$, dinding $B$ sebesar $1,600 \times 10^{-7}$ $\mathrm{mR} / \mathrm{h}$, dinding $C$ sebesar $6,217 \times 10^{-8} \mathrm{mR} / \mathrm{h}$ dan dinding $\mathrm{D}$ sebesar 7,668 $\times 10^{-8} \mathrm{mR} / \mathrm{h}$. Hasil perhitungan laju paparan radiasi sinar-X pada dinding di luar laboratorium diperoleh sebesar $0 \mathrm{mR} / \mathrm{h}$. Dari hasil tersebut terlihat bahwa laju paparan radiasi sinar-X di laboratorium diagnostik ATRO Bali masih di bawah nilai batas dosis (NBD) yang direkomendasikan oleh Perka Bapeten No. 8 tahun 2011 sebesar 0,57 mR/h untuk pekerja radiasi dan 0,03 $\mathrm{mR} / \mathrm{h}$ untuk masyarakat.
\end{abstract}

Kata kunci: Radiasi sinar-X, dosis paparan, laju paparan, radiasi primer, efektivitas dinding.

\begin{abstract}
Research has been carried out on the rate of exposure to X-ray radiation on the walls of the ATRO Bali diagnostic laboratory. The dose of $X$-ray radiation exposure was measured using a surveymeter indoors and outdoors on the primary radiation retaining wall (A), secondary radiation retaining wall $(B$ and $D)$ and leakage radiation retaining wall $(C)$ by setting the exposure factor at 80 $k V$ tube voltage, $200 \mathrm{~mA}$ tube current and 0.160 seconds time. The results of the radiation exposure dose measurement on all walls are used to calculate the radiation exposure rate. The results of the calculation of the average rate of exposure to $X$-ray radiation on wall $A$ is $1.106 \times 10^{-7} \mathrm{mR} / \mathrm{h}$, wall $B$ is $1.600 \times 10^{-7} \mathrm{mR} / \mathrm{h}$, wall $C$ is $6.217 \times 10^{-8} \mathrm{mR} / \mathrm{h}$ and wall $\mathrm{D}$ of $7.668 \times 10^{-8} \mathrm{mR} / \mathrm{h}$. The results of the calculation of the rate of exposure to $X$-ray radiation on the walls outside the laboratory were obtained at $0 \mathrm{mR} /$ hour. From these results it can be seen that the rate of exposure to $X$-ray radiation in the Bali ATRO diagnostic laboratory is still below the dose limit value (NBD) recommended by Bapeten Perka No. 8 of 2011 amounted to $0.57 \mathrm{mR} / \mathrm{h}$ for radiation workers and $0.03 \mathrm{mR} / \mathrm{h}$ for the community.
\end{abstract}

Key words: $X$-ray radiation, irradiation doses, radiation exposure rate, primary radiation, wall effectiveness.

\section{Pendahuluan}

Radiasi merupakan pemancaran energi dalam bentuk gelombang atau partikel yang dipancarkan oleh sumber radiasi atau zat radioaktif [1]. Radiasi dimanfaatkan dalam bidang industri, pertanian, transportasi dan kesehatan. Pemanfaatan radiasi pengion dalam bidang kesehatan sebagai sinar-X yang digunakan untuk mendiagnosis adanya suatu penyakit dalam bentuk gambaran anatomi tubuh yang ditampilkan dalam film radiografi [2].

Radiasi memiliki manfaat dan menimbulkan efek radiasi. Efek radiasi bisa berdampak pada penerimaan dosis paparan yang berlebih kepada pekerja maupun masyarakat. Radiasi dipancarkan dari sumber radiasi ke segala arah sehingga semakin dekat tubuh dengan sumber radiasi maka paparan radiasi yang diterima semakin besar. Paparan radiasi sebagian akan menjadi radiasi hambur saat mengenai 
materi. Radiasi hambur ini akan menambah jumlah dosis radiasi yang diterima [3]. Upaya untuk melindungi pekerja tersebut adalah dengan menggunakan proteksi radiasi. Proteksi radiasi yang harus diterapkan meliputi jarak, waktu dan penahan radiasi. Jarak pekerja diharapkan sejauh mungkin dari sumber radiasi, waktu sesingkat mungkin berada pada daerah radiasi dan untuk penahan radiasi harus menggunakan alat pelindung diri (APD) dan berlindung dibalik dinding saat eksposi [4].

Penahan radiasi dibedakan menjadi dua yaitu penahan sumber dan penahan struktural. Penahan sumber sudah menyatu dengan peralatan sinar-X sedangkan penahan struktural dibedakan menjadi dua yaitu penahan radiasi primer yang memberikan perlindungan terhadap sinar guna dan penahan radiasi sekunder memberikan perlindungan terhadap radiasi sekunder hambur dan radiasi sekunder bocor [5]. Berdasarkan Perka Bapeten No. 8 tahun 2011 tentang keselamatan radiasi dalam penggunaan pesawat sinar-X mengenai program jaminan mutu desain bangunan, NBD harus memenuhi persyaratan untuk pekerja radiasi yaitu $10 \mathrm{mSv}$ per tahun atau $0,2 \mathrm{mSv}$ per minggu setara dengan $0,57 \mathrm{mR}$ per jam dan untuk masyarakat sebesar $0,5 \mathrm{mSv}$ per tahun atau $0,01 \mathrm{mSv}$ per minggu setara dengan $0,03 \mathrm{mR}$ per jam [6].

Guna mencegah dan meminimalisir bahaya radiasi, maka diperlukan penelitian tentang laju paparan radiasi sinar-X pada dinding ruangan laboratorium diagnostik ATRO Bali untuk melindungi pekerja radiasi, staf, dan mahasiswa mengingat radiasi tidak berbau dan tidak tampak tetapi berbahaya bagi kesehatan dan keselamatan. Paparan radiasi secara kontinyu dapat menyebabkan gangguan kesehatan hingga kematian [7].

\section{Landasan Teori}

Sinar-X merupakan pancaran gelombang elektromagnetik dengan panjang gelombang yang sangat pendek berkisar antara 10 nanometer sampai 100 pikometer. Sinar-X bermanfaat di dalam dunia medis karena sifatnya dapat menembus bahan. Semakin tinggi tegangan yang dipakai, semakin besar daya tembusnya. Sinar-X dengan energi rendah (12 keV-100 keV) umumnya digunakan sebagai radiodiagnostik, sedangkan sinar- $\mathrm{X}$ dengan energi tinggi (100 keV-3 MeV) umumnya dimanfaatkan untuk radioterapi [8].

Dosis serap dapat ditentukan dari nilai paparan dengan hubungan sebagai berikut

$$
D=f . X
$$

Dimana $f$ adalah faktor konversi dari paparan ke dosis serap dan untuk $X$ adalah paparan. Bila medium yang digunakan udara, maka $f=0,877 \mathrm{rad} / \mathrm{R}$. Untuk keperluan proteksi radiasi, ditetapkan nilai konversi dosis $(f)$ besarnya $=1 \mathrm{rad} / \mathrm{R}[9]$.

Dosis ekivalen adalah dosis serap dikalikan faktor bobot radiasi. Faktor bobot radiasi ini dikaitkan dengan kemampuan radiasi dalam membentuk pasangan ion per satuan panjang lintasan, semakin banyak pasangan ion yang dapat dibentuk persatuan panjang lintasan, maka semakin besar pula nilai faktor bobot radiasi tersebut. Faktor bobot radiasi untuk elektron (radiasi beta), foton (gamma) dan sinar-X bernilai 1 sedangkan untuk radiasi alfa bernilai 20. Secara matematis dosis ekivalen dituliskan seperti pada Persamaan (2) [10].

$$
H=D . W r
$$

$H$ adalah dosis ekivalen, $D$ adalah dosis serap dan untuk $W r$ adalah faktor bobot.

Interaksi radiasi pengion dengan tubuh manusia akan mengakibatkan terjadinya efek radiasi. Efek radiasi diawali dengan peristiwa yang terjadi pada tingkat molekuler dan akan berkembang menjadi gejala klinis. Sifat dan keparahan gejala, dan juga waktu kemunculannya sangat bergantung pada jumlah dosis radiasi yang diserap dan laju penerimaannya. Efek radiasi dibedakan menjadi dua yaitu efek deterministik dan efek stokastik. Efek deterministik dapat terjadi akibat dari paparan radiasi pada seluruh tubuh maupun lokal. Efek ini timbul apabila dosis yang diterima di atas dosis ambang dan umumnya timbul beberapa saat setelah terpapar radiasi. Efek stokastik adalah efek yang terjadi sebagai akibat paparan radiasi dengan dosis yang menyebabkan terjadinya perubahan pada sel [11].

Surveymeter digunakan untuk mengukur dosis paparan radiasi di lokasi pengukuran secara langsung [12]. Surveymeter berfungsi untuk memeriksa daerah aman bagi pekerja radiasi atau pekerja non radiasi dan memeriksa kebocoran radiasi sumber. Terdapat tiga hal penting yang perlu diperhatikan sebelum menggunakan surveymeter yaitu memeriksa baterai, memeriksa sertifikat kalibrasi, dan mempelajari pengoperasian dan pembacaan alat [13]. 
Pesawat sinar-X adalah suatu alat yang digunakan untuk melakukan diagnosa medis dengan menggunakan sinar-X. Sinar-X yang dipancarkan dari tabung diarahkan pada bagian tubuh yang akan didiagnosa. Berkas sinar-X tersebut akan menembus bagian tubuh dan akan ditangkap oleh film, sehingga akan terbentuk gambar dari bagian tubuh yang disinari. Sebelum pengoperasian pesawat sinar$\mathrm{X}$ perlu dilakukan pengaturan faktor eksposi untuk mendapatkan sinar-X yang dikehendaki. Faktor eksposi tersebut adalah tegangan tabung $(\mathrm{kV})$, arus tabung $(\mathrm{mA})$ dan waktu paparan (s) [14].

\section{Metode Penelitian}

Penelitian dilaksanakan di Akademi Teknik Radiodiagnostik dan Radioterapi (ATRO) Bali. Alat-alat yang digunakan pada penelitian ini adalah pesawat sinar-X merk medical Instrument System (MIS) tipe MXHF-1300R, surveymeter merk Fluka dan meteran.

Langkah pertama yang dilakukan untuk pengukuran dosis paparan radiasi yaitu menentukan jarak sumber ke dinding penahan radiasi primer $\left(l_{l}\right)$, jarak sumber ke dinding penahan radiasi sekunder hambur $\left(l_{2}\right.$ dan $\left.l_{4}\right)$ dan jarak sumber ke dinding penahan radiasi sekunder bocor $\left(l_{3}\right)$. Menentukan pengukuran di dalam dan di luar ruangan yaitu dinding penahan radiasi primer (A dan a), dinding penahan radiasi sekunder hambur $(\mathrm{B}, \mathrm{b}$ dan $\mathrm{D}, \mathrm{d})$ dan dinding penahan radiasi sekunder bocor $(\mathrm{C}$ dan $\mathrm{c})$. Pada dinding penahan radiasi primer dibagi menjadi tiga titik pengukuran dengan jarak $138,7 \mathrm{~cm}$ yang ditandai dengan $\mathrm{A}_{1}, \mathrm{~A}_{2}, \mathrm{~A}_{3}$ (di dalam ruangan) dan $\mathrm{a}_{1}, \mathrm{a}_{2}, \mathrm{a}_{3}$ (di luar ruangan). Dinding penahan radiasi sekunder hambur masing-masing dibagi menjadi empat titik dengan jarak $137,5 \mathrm{~cm}$ yang ditandai dengan $\mathrm{B}_{1}, \mathrm{~B}_{2}, \mathrm{~B}_{3}, \mathrm{~B}_{4}$ dan $D_{1}, D_{2}, D_{3}, D_{4}$ (di dalam ruangan), sedangkan di luar ruangan ditandai dengan $b_{1}, b_{2}, b_{3}, b_{4}$ dan $d_{1}, d_{2}$, $\mathrm{d}_{3}, \mathrm{~d}_{4}$. Untuk dinding penahan radiasi sekunder bocor dibagi menjadi tiga titik dengan jarak $138,7 \mathrm{~cm}$ yaitu $\mathrm{C}_{1}, \mathrm{C}_{2}, \mathrm{C}_{3}$ (di dalam ruangan) dan $\mathrm{c}_{1}, \mathrm{c}_{2}, \mathrm{c}_{3}$ (di luar ruangan). Pembagian titik pengukuran di dalam maupun di luar ruangan ditunjukkan pada Gambar 1 . Sebelum pengukuran, pesawat sinar-X dinyalakan dan dilakukan prosedur warming up. Selanjutnya mengatur faktor eksposi dengan tegangan tabung 80 $\mathrm{kV}$, arus tabung sebesar $200 \mathrm{~mA}$ dalam waktu eksposi $0,060 \mathrm{~s}$, kemudian menyalakan surveymeter dalam mode integral (mengakumulasi dosis yang terukur) dan meletakkan di titik pengukuran. Arahkan tabung sinar-X ke dinding primer, lalu dieksposi dan mencatat dosis paparannya. Langkah diatas dilakukan juga untuk dinding sekunder hambur dan sekunder bocor dengan arah tube pada dinding primer.

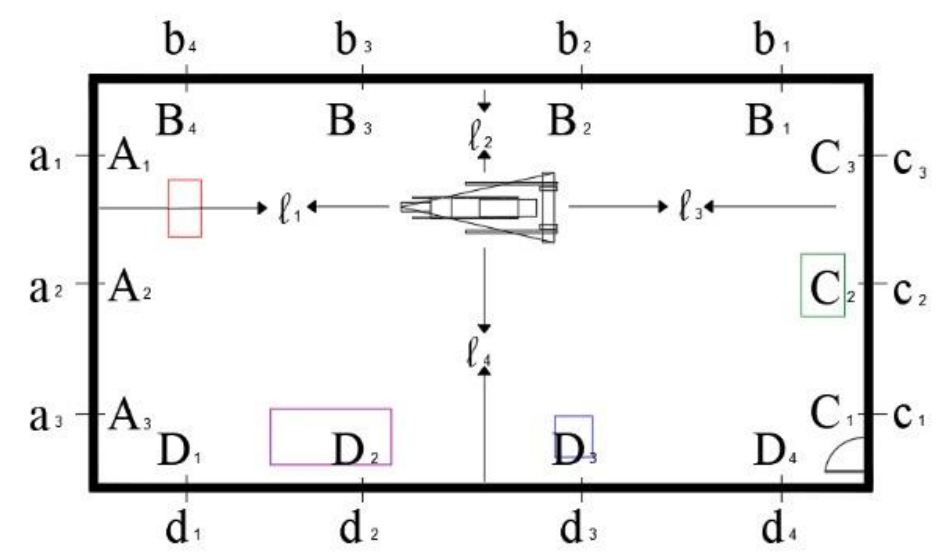

Gambar 1. Titik pengukuran di dalam ruangan dan di luar ruangan.

\section{Hasil Dan Pembahasan}

Hasil pengukuran dosis paparan sinar-X pada semua dinding baik di dalam maupun di luar ruangan dengan faktor eksposi berupa tegangan tabung $80 \mathrm{kV}$, arus tabung $200 \mathrm{~mA}$ dalam waktu 0,160 detik digunakan untuk menghitung laju paparan radiasi sinar-X. Satuan dosis paparan yang diukur oleh surveymeter dalam satuan mikroSievert $(\mu \mathrm{Sv})$. Satuan ini dikonversi menjadi mikroSievert per jam $(\mu \mathrm{Sv} / \mathrm{h})$ dan dikalikan dengan faktor kalibrasi alat sebesar $1,09 \mu \mathrm{Sv} / \mathrm{h}$, yang selanjutnya dikonversi lagi menjadi miliSievert per jam $(\mathrm{mSv} / \mathrm{h})$. Perhitungan rata-rata laju dosis ekivalen menggunakan standar deviasi dan dengan Persamaan 2 diperoleh nilai laju dosis serap dalam satuan miliGray per jam $(\mathrm{mGray} / \mathrm{h})$. Dari nilai laju dosis serap ini dilakukan perhitungan laju paparan radiasi menggunakan Persamaan 1 dalam satuan miliRontgen per jam $(\mathrm{mR} / \mathrm{h})$. Hasil perhitungan laju paparan radiasi pada dinding di dalam ruangan dapat dilihat pada Tabel 1. 
X-Ray Radiation Exposure Rate on the Walls of ATRO Bali Diagnostic Laboratory ........

(Nunung Purwati Dewi, dkk)

Tabel 1. Hasil perhitungan laju paparan radiasi di dalam ruangan.

\begin{tabular}{ccccc}
\hline $\begin{array}{c}\text { Titik } \\
\text { Pengukuran }\end{array}$ & $\begin{array}{c}\text { Laju Paparan A } \\
(\mathrm{mR} / \mathrm{h})\end{array}$ & $\begin{array}{c}\text { Laju Paparan B } \\
(\mathrm{mR} / \mathrm{h})\end{array}$ & $\begin{array}{c}\text { Laju Paparan C } \\
(\mathrm{mR} / \mathrm{h})\end{array}$ & $\begin{array}{c}\text { Laju Paparan D } \\
(\mathrm{mR} / \mathrm{h})\end{array}$ \\
\hline 1 & $2,705 \times 10^{-7}$ & $1,093 \times 10^{-8}$ & $0,437 \times 10^{-7}$ & $1,892 \times 10^{-8}$ \\
2 & $0,394 \times 10^{-7}$ & $2,738 \times 10^{-7}$ & $0,952 \times 10^{-7}$ & $0,716 \times 10^{-7}$ \\
3 & $2,185 \times 10^{-8}$ & $1,367 \times 10^{-7}$ & $0,476 \times 10^{-7}$ & $0,874 \times 10^{-7}$ \\
4 & - & $2,184 \times 10^{-7}$ & - & $1,288 \times 10^{-7}$ \\
Nilai Rata-rata & $1,106 \times 10^{-7}$ & $1,600 \times 10^{-7}$ & $6,217 \times 10^{-8}$ & $7,668 \times 10^{-8}$ \\
\hline
\end{tabular}

Dari hasil perhitungan pada Tabel 1, diperoleh rata-rata laju paparan radiasi pada dinding A sebesar $1,106 \times 10^{-7} \mathrm{mR} / \mathrm{h}$, dinding $B$ sebesar $1,600 \times 10^{-7} \mathrm{mR} / \mathrm{h}$, dinding $\mathrm{C}$ sebesar $6,217 \times 10^{-8} \mathrm{mR} / \mathrm{h}$ dan dinding D sebesar 7,668 $\times 10^{-8} \mathrm{mR} / \mathrm{h}$. Nilai rata-rata laju paparan radiasi terbesar yaitu pada dinding $\mathrm{B}$ yaitu dinding sekunder di dalam ruangan. Hal ini disebabkan karena dinding B terletak paling dekat dengan sumber radiasi atau xray tube jika dibandingkan dengan dinding yang lain dan untuk hasil perhitungan laju paparan radiasi di luar ruangan untuk semua titik pengukuran sebesar $0 \mathrm{mR} / \mathrm{h}$. Hal ini disebabkan karena tidak ada radiasi yang dapat melewati dinding. Mengacu pada Perka Bapeten No. 8 tahun 2011 bahwa NBD yang direkomendasikan untuk pekerja radiasi sebesar $0,57 \mathrm{mR} / \mathrm{h}$ dan untuk masyarakat $0,03 \mathrm{mR} / \mathrm{h}$, maka hasil perhitungan laju paparan radiasi sinar-X di laboratorium ATRO Bali masih di bawah dosis yang direkomendasikan. Jadi, dinding yang ada cukup efektif menahan laju paparan radiasi primer maupun radiasi sekunder hambur dan sekunder bocor sehingga dinyatakan aman bagi pekerja radiasi, pekerja non radiasi maupun masyarakat umum.

\section{Kesimpulan}

Hasil perhitungan laju paparan radiasi di dalam ruangan sebesar $1,106 \times 10^{-7} \mathrm{mR} / \mathrm{h}$ untuk dinding A, $1,600 \times 10^{-7} \mathrm{mR} / \mathrm{h}$ untuk dinding $\mathrm{B}, 6,217 \times 10^{-8} \mathrm{mR} / \mathrm{h}$ untuk dinding $\mathrm{C}, 7,668 \times 10^{-8} \mathrm{mR} / \mathrm{h}$ untuk dinding $\mathrm{D}$ dan $0 \mathrm{mR} / \mathrm{h}$ untuk semua dinding di luar ruangan laboratorium. Hasil perhitungan laju paparan radiasi di dalam dan di luar ruangan menunjukkan bahwa nilai paparan radiasi pada dinding masih berada pada rentang yang direkomendasikan oleh Perka Bapeten No. 8 tahun 2011 yang menetapkan NBD sebesar $0,57 \mathrm{mR} / \mathrm{h}$ untuk pekerja radiasi dan $0,03 \mathrm{mR} / \mathrm{h}$ untuk masyarakat. Jadi dinding yang ada cukup efektif menahan laju paparan radiasi primer maupun radiasi sekunder sehingga dinyatakan aman bagi pekerja radiasi, pekerja non radiasi maupun masyarakat umum.

\section{Ucapan Terima Kasih}

Ucapan terimakasih ditujukan kepada seluruh staff di Akademi Teknik Radiodiagnostik dan Radioterapi (ATRO) Bali atas izin dan bantuannya sehingga penelitian ini dapat terlaksana, serta staf dosen Program Studi Fisika, FMIPA, UNUD yang telah memberikan saran serta masukan terkait penelitian ini.

\section{Pustaka}

[1] Syahria, E. Setiawati, K. S. Firdausi, Pembuatan Kurva Isodosis Paparan Radiasi di Ruang Pemeriksaan Instalasi Radiologi RSUD Kabupaten Kolaka Sulawesi Tenggara, Berkala Fisika, vol. 5, 2012, pp. 123-132.

[2] Z. Alatas, Efek Radiasi Pengion dan Non Pengion pada Manusia, Buletin Alara, vol. 5, 2005, pp. 99-112.

[3] M. F. Ulum, Prinsip Dasar Proteksi Radiasi dalam Diagnostik, Proceedings Join Meeting of the 3 rd International Meeting on AZMWC2008 and KIVNAS X PDHI, Bogor, ISBN, 2008.

[4] Agustiar, Desain Ruangan Pesawat Sinar-X Kapasitas 125 kV dan 200 mA Rumah Sakit Siti Aminah Bumi Ayu Jawa Tengah, Prima, Pusat Kemitraan Teknologi Nuklir-Batan, vol. 6, no. 11, 2009.

[5] Kristiyanti, S. Ferry, Perancangan Ruangan Radiografi Medik di Sekolah Tinggi Teknik Nuklir, Seminar Nasional VIII SDM Teknologi Nuklir Yogyakarta,2012.

[6] Badan Pengawas Tenaga Nuklir, Peraturan Kepala BAPETEN No. 8 Tahun 2011 tentang Keselamatan Radiasi dalam Penggunaan Pesawat Sinar-X Radiologi Diagnostik dan Intervensional, Jakarta, 2011. 
[7] S. Sari, Pengembangan Sistem Manajemen Keselamatan Radiasi Sinar-X di Unit Kerja Radiologi Rumah Sakit XYZ Tahun 2011, Skripsi, Program Sarjana, Fakultas Kesehatan Masyarakat Departemen Keselamatan dan Kesehatan Kerja, Universitas Indonesia, 2012.

[8] Rasad, Radiologi Diagnostik, Edisi Kedua, Jakarta, Balai Penerbit FK UI, 2005.

[9] BATAN, Dasar Fisika Radiasi, Pusat Pendidikan dan Pelatihan Badan Tenaga Nuklir Nasional, Jakarta, 2015.

[10] M. Akhadi, Dasar-Dasar Proteksi Radiasi, PT. Rineka Cipta, Jakarta, 2000.

[11] E. Hiswara, Proteksi dan Keselamatan Radiasi di Rumah Sakit, BATAN Press, Jakarta, 2015.

[12] Martem, dkk, Pengukuran Dosis Radiasi Ruangan Radiologi II Rumah Sakit Gigi dan Mulut (RSGM) Baiturrahmah Padang Menggunakan Surveymeter Unfors-XI, Jurnal Fisika Unand, Jurusan Fisika FMIPA Universitas Andalas, Padang, Indonesia, vol. 4, no. 4, 2015.

[13] BATAN, Alat Ukur Radiasi Kawasan Nuklir Serpong, Tangerang Selatan, 2013.

[14] A. Pasinringi, Pengujian Kesesuaian antara Lapangan Penyinaran Kolimator dengan Berkas Radiasi yang dihasilkan pada Pesawat Sinar-X Mobile di Rumah Sakit Umum Daerah Tani dan Nelayan Gorontalo,Skripsi, Jurusan Fisika Program Studi Konsentrasi Fisika Medik, Fakultas Matematika dan Ilmu Pengetahuan Alam, Universitas Hasanuddin, 2012. 